\section{Mecanismos de selección y verificación de información brindada por ciudadanos a través del WhatsApp en la producción informativa de canales de noticias peruanos. Estudio de caso: RPP Noticias y Canal N}

Selection and verification methods of the information provided by citizens through WhatsApp and their role in the production of peruvian channel news. Case Study: RPP Noticias and Canal N

DOI: http://dx.doi.org/10.18566/comunica.n40.a03

Recibido: 22/03/2019 - Aceptado: 11/06/2019

\section{Resumen}

El presente estudio describe los mecanismos de selección y verificación que realizan dos canales de noticias en Perú con respecto a la información brindada por ciudadanos a través de sus líneas de WhatsApp, partiendo desde los estudios sobre periodismo ciudadano. Se aplicaron entrevistas semiestructuradas a los periodistas responsables de gestionar dicha información en los noticieros. Así también, se analizaron las noticias que fueron transmitidas a partir de dichas informaciones. Entre los resultados que se hallaron destacan que, en gran medida, los canales de noticias utilizan los mismos criterios de selección de información que usa el periodismo de televisión tradicional, y que la información que llega al WhatsApp es usada como una fuente más de información del medio. comunicación

número 40

Enero - junio

2019 | pp. 35-52

\section{Mg. Mercedes}

\section{Palomino Gonzales}

Magíster en Guion de Cine y

Televisión por la Universidad Carlos III de Madrid (España) y licenciada en Ciencias de la Comunicación por la Universidad de San Martín de Porres (Perú). Es corresponsal de la Agencia Efe en Perú y docente de la Facultad de Comunicaciones en la USMP. Investiga sobre comunicación social y periodismo. mpalominiog@usmp. pe ORCID: https: / / orcid. org/0000-0002-4876-2755

Palabras clave Periodismo de televisión, Noticieros, WhatsApp, Periodismo ciudadano

Keywords Broadcast journalism, news, WhatsApp, citizen journalism, street journalism 


\section{Abstract}

This study describes the selection and verification mechanisms carried out by two news channels in Peru regarding the information provided by citizens through their WhatsApp lines, starting from the studies on citizen journalism. Semi-structured interviews were conducted with the journalists in charge of managing this information on the news. Likewise, the news that were transmitted from said information were analyzed. Among the results it was found that, to a great extent, news channels use the same information selection criteria as traditional television journalism, and that the information that arrives through WhatsApp is used as another information source on the news channels.

\section{Introducción}

La creciente penetración de los celulares smartphone con acceso a Internet ha elevado los índices de interacción de los peruanos a través de estos dispositivos. Según un último estudio de la compañía de investigación de marketing Comscore del 2018, el mercado digital peruano es uno de los que presenta un mayor dinamismo en la región respecto a este uso, con un 40\% de penetración. Entre las principales actividades de sus usuarios figuran el uso de redes sociales, con un $90 \%$ del total, según lo señala el estudio Digital in de 2018 (Kemp, 2018).

Esta realidad, conocida también por los medios de comunicación peruanos y específicamente los medios que serán analizados en esta investigación: Canal $N$ y RPP Noticias, ha motivado su participación en redes sociales como Facebook y Twitter. Ambas redes sociales, además de ser usadas para compartir contenidos con sus audiencias, también son utilizadas como espacio de interacción con ellas. No obstante, desde el 2016, una nueva red social ha ocupado un uso prioritario en los medios. Se trata de la red de mensajería instantánea WhatsApp que, según un estudio de GFK (2017), es la segunda red social más utilizada por los peruanos con 59\% de usuarios, solo por debajo de Facebook (89\%). Esto ha despertado un gran interés de los productores de noticias, tal como se evidencia en los principales canales de televisión peruanos y en los canales temáticos de noticias, que han puesto a disposición de sus audiencias un número de contacto de WhatsApp.

Una de las ventajas del WhatsApp percibidas por los medios de comunicación es la capacidad que tiene de ser un medio de transmisión de audios, fotografías y vídeos a través de un número telefónico. Así, al poder contar con un número de contacto del emisor de la información, el periodista tiene la posibilidad de ampliarla casi de manera inmediata. No es de extrañar por ello que a partir del 2016 se aprecie un marcado interés de los medios 
Por otro lado, la familiaridad del uso del WhatsApp eleva las posibilidades de interacción de las audiencias con los medios, potenciando el periodismo participativo, que, para el desarrollo de esta investigación, se entiende como el papel activo de los ciudadanos en el proceso de colectar, reportar, analizar y diseminar la información (Bowman y Willis, 2003, p. 9).

En esa línea, los canales de noticias analizados desde julio a octubre del 2018 han habilitado números de teléfonos dedicados a ser líneas de contacto de WhatsApp. Su interés por nutrirse de la información que su audiencia produce se hace explícito en la recordación constante de sus líneas de WhatsApp, la que es realizada tanto en pantalla como a través de sus redes sociales. Es así que el objetivo de esta investigación es conocer qué ocurre una vez que la información es enviada a manera de mensaje al WhatsApp del medio. A través de entrevistas a los periodistas responsables de seleccionar la información y de corroborar su autenticidad, se constatará si estas responden a procesos similares a la de la producción noticiosa tradicional. En segundo término, se realizará una descripción de lo hallado en las emisiones de ambos canales que estos señalan como fuente a informaciones transmitidas por WhatsApp.

\section{Antecedentes del periodismo participativo o ciudadano}

El negocio de los medios de comunicación pasa por una larga transición desde que las nuevas tecnologías irrumpieron en la vida diaria de los ciudadanos para crear una diversidad de oportunidades en la transmisión y obtención de la información. Tal es el impacto a nivel cualitativo como cuantitativo que, a partir de la entrada de los blogueros en el mundo de la información, se hace necesaria la creación de léxicos para referirse a su labor, tal como los del periodista participativo o periodista ciudadano.

El periodismo participativo o periodismo ciudadano son los dos términos más empleados para referirse a la participación de los ciudadanos en el ámbito de la información de interés general o periodístico. Ellos son quienes juegan un papel activo en la producción de la noticia, así como en su difusión (Bowman y Willis, 2003). Además, como explica Meso (2005), tiene entre sus características promover la participación ciudadana en el procesamiento de 
la información, y en la formación de opinión. Así, se trata de la intervención de sujetos no periodistas en el ámbito informativo.

Al unir los términos periodista y ciudadano, existen voces que se oponen a la idea de nombrar periodista a aquel que no cuenta con una formación académica que dote al productor de la noticia de los principios éticos de la profesión. Sánchez, por ejemplo, considera que "el intercambio de papeles no es posible porque se distorsiona el panorama de la comunicación" y porque "el periodista tiene un compromiso con la verdad, la diferenciación entre información y opinión, la verificación de las noticias y las normas éticas que le incumben" (Espiritusanto y Sánchez, 2013, p. 56). Posición que comparte Rost (citado en Meso, 2013, p. 66), quien duda de si el envío de fotos y vídeos es más una colaboración a la producción noticiosa que periodismo.

De la misma manera, Salvat y Serrano (2011) explican que el término responde más a un cambio en el ejercicio del periodismo tradicional y su relación con sus audiencias en pro de una aparente democratización de la información. "El llamado periodismo ciudadano se enfrentaría a ese periodismo tradicional caracterizado por un exceso de dependencia respecto de las fuentes profesionales y que ejerce como poder frente a una 'ciudadanía' pasiva” (Salvat y Serrano, 2011, p. 70).

Chillón (2010, p. 295) también lo explica en esa misma línea como "la necesidad ciudadana de participar en la construcción de la realidad social", que a su vez ha transformado todas las estructuras de los medios de comunicación, incluyendo el modelo de negocio. A partir de la irrupción de los nuevos medios es inevitable una revolución que, como explica Gillmor (citado en Maciá, 2007, pp. 126-127), los periodistas comprendan que las audiencias ahora pueden saber tanto como saben ellos sobre un hecho que reportan. Por ello, los periodistas deberán abrazarse a los valores fundamentales de la profesión que son la exactitud y la imparcialidad, sumados a la tan importante capacidad de ampliar la conversación y proporcionar contexto al hecho noticioso, pues serán sus valores diferenciales.

Asimismo, interesa anotar que a partir de la irrupción de las nuevas tecnologías y su amplia penetración en todo el mundo, el concepto de ciudadanía de hoy está estrechamente ligado a una autopercepción mediada por un mayor acceso a las herramientas móviles (Espiritusanto y Sánchez, 2013). Esta característica coincidentemente acerca el concepto de ciudadanía a su acepción griega, de ser sujeto activo y pleno de derechos, tal como ocurre en el ejercicio del periodismo ciudadano, donde estos son sujetos capaces de generar y difundir contenidos. Por lo que, como explican Salvat y Serrano (2011, p. 71), el periodismo participativo o ciudadano "nace 
con el objetivo de formar parte activa de los procesos de la creación de la información realizada cotidianamente por los medios".

En esa línea, una de las formas de colaboración que hoy se estimula más desde los medios tradicionales es la de transmisión de información a través de WhatsApp. Este tipo de práctica informativa se ubica, según la diferenciación que hace Chillón (2010), en un tipo de periodismo ciudadano cuya dinámica de participación es propuesta por los medios de comunicación.

Su característica primordial es que en esta práctica los medios son los que ofrecen un espacio al ciudadano, a partir del cual se crea un beneficio mutuo: tanto del medio por presentar información relevante, como para el ciudadano o periodista ciudadano, que genera una visibilidad y una reputación que de otra manera hubiera sido muy difícil de acceder. Varela (2005, p. 32) ha llamado a este tipo de periodismo: periodismo digital 3.0, un periodismo que implica diálogo y conversación, una socialización de la información que podría ser bien aprovechada por los medios "para reconstruir una relación de confianza entre los medios y la audiencia a través de la interactividad".

Asimismo, según la tipología de periodismo ciudadano que plantea Espiritusanto (2011), la participación que se estimula en las audiencias de estos medios a través del WhatsApp es la altruista, o por solidaridad, o porque se defiende una causa o una posición, pues estos medios que analizamos no están ofreciendo ningún tipo de recompensa a cambio de la información ciudadana.

En el Perú existe un constante incentivo de los canales de televisión para la producción de información de sus audiencias. Ello se refleja en que los cinco principales canales peruanos (TV Perú, ATV, América Televisión, Latina Televisión y Panamericana), así como todos los canales temáticos de noticias (RPP Noticias, Canal N, ATV +, TV Perú 7.3), hacen un llamado a sus audiencias para que se pongan en contacto a través de su número de WhatsApp.

Esto ha venido abriendo paso a un cada vez más robusto diálogo entre medios y audiencia, donde los medios reconocen ya no ser el centro de la información. Así lo explica Gillmor (citado en Bowman y Willis, 2003, p. 6) en los principios que rigen el actual movimiento We media (Nosotros, el medio): "Mis lectores saben más que yo", "Esto no es una amenaza, sino una oportunidad", "Podemos usar este principio para crear juntos algo intermedio entre un seminario y una conversación que nos eduque a todos". 


\section{Antecedentes del uso del WhatsApp en la producción periodística}

En los últimos años, los periodistas se han embarcado casi indefectiblemente en el uso de las redes sociales como Facebook y Twitter para su trabajo diario, reconociendo su importancia en la transmisión y recepción de información. Los medios de comunicación, además, han alentado entre sus periodistas una cultura 2.0 que integra las redes sociales a su ejercicio periodístico (Curiel, 2015).

En el caso de Twitter, el servicio microblogging que permite a sus usuarios publicar mensajes de temática variada siempre y cuando tengan como máximo 280 caracteres, es usado por los medios, además de realizar la difusión de enlaces de sus notas periodísticas, también para hacer seguimiento de cuentas de ciertos usuarios que podrían convertirse en fuentes periodísticas o que son figuras públicas (Carabaza y Pérez, 2013).

En esa misma línea, en los últimos cinco años el periodismo ha sido testigo de cómo una nueva red de mensajería denominada WhatsApp ha ido acumulando un gran número de usuarios que, según un informe recogido por Smith (citado en Azeema y Nazuk, 2017, p.250), "transmite alrededor de 42.000 millones de mensajes de sus 320 millones de usuarios activos por día".

Nacida en el 2009, el WhatsApp es una aplicación de mensajería para teléfonos inteligentes o smartphones, que tiene como característica identificar al usuario con su número de teléfono para así poder enviar y recibir mensajes a través de Internet. Además, tiene un servicio de mensajería multimedia, permite acceder a la libreta de contactos del celular, crear grupos, reenviar mensajes, imágenes, vídeos y grabaciones de audios. No tiene restricciones de uso de edad excepto las marcadas por el ámbito geográfico desde donde es usada. Por ejemplo, en la Unión Europea, se establece una edad de 16 años como mínimo.

En el Perú, el WhatsApp se ubica actualmente como la segunda red social más usada (GFK, 2017), solo por detrás de Facebook y empatada con YouTube, fenómeno que se condice con su éxito mundial. Por ello, si bien no existen datos exactos sobre su uso por periodistas en Perú para la cobertura de noticias, este va en línea a la tendencia periodística mundial que la reconoce "como una poderosa herramienta para reporteros" (Ossorio, 2016). Zárate (2018) señala sobre el uso de WhatsApp por los periodistas peruanos que lo utilizan "para facilitar una rapidez de procedimientos tanto interno como externo en los medios de comunicación", en referencia a que a través de este se establece contacto entre pares, como con fuentes. 
La preferencia de su uso en los grupos de periodistas se debe a que es una herramienta que brinda las posibilidades de transmisión de archivos de texto, imágenes, audios y vídeos, lo que hace posible una diversidad de contenidos noticiosos para los medios.

En esa línea, el WhatsApp ha sido reconocido ya por muchos autores como una herramienta de uso periodístico (Reid, 2016). Pero, además, su uso es también alentado actualmente por las empresas de comunicación peruanas que, a través de anuncios en sus medios, así como en sus redes sociales, brindan un número de WhatsApp para el contacto directo entre audiencia-medio-audiencia, con el que estos esperan poder recibir información de primera mano.

A este tipo de uso del WhatsApp, en otros países ya se han sumado el de transmisión de información por suscripción a las audiencias. Un ejemplo de ello fue el caso de The New York Times by WhatsApp en Estados Unidos. Como explica Welsh (2015), en julio del 2015 el New York Times transmitió por primera vez su información vía WhatsApp. Esta fue en relación a la visita del Papa Francisco a los países sudamericanos de Ecuador, Bolivia y Paraguay, por lo que un mes antes anunció que pondría a disposición de sus lectores un contenido gratuito transmitido por esta red de mensajería. Este consistía en suscribirse a través de un número de WhatsApp, con el texto POPE, para poder recibir las actualizaciones acerca de la gira del sumo pontífice. Desde luego, también daba la opción de retirarse, a través de un mensaje UNSUSCRIBE.

En el Perú, actualmente los cinco principales canales de televisión de señal abierta, así como los cuatro canales temáticos de noticias, brindan un número de WhatsApp para la transmisión de información desde el ciudadano hasta el medio tradicional para: (1). Ampliar el vínculo de los canales de noticias con sus audiencias productoras, (2). Servirse de las posibilidades que esta acción propia del ejercicio reporteril ofrece al medio gracias a los ciudadanos, ya que es conocido que una de las dificultades de los medios tradicionales frente a los nuevos medios es la mayor inmediatez de estos últimos. En ese sentido, la información de los ciudadanos a través del WhatsApp se constituye como una enorme oportunidad para los medios tradicionales de optimizar sus tiempos.

Sin embargo, se observa también que, como ya ocurría con otras redes sociales como Twitter, existe el peligro del esparcimiento de rumores infundados. Como señala Overholser (citado en Carabaza y Pérez, 2014, p. 142), si bien estas redes tienen un enorme potencial para acceder a las fuentes directas, la información debe ser tomada con suma cautela, por lo que exigirá del periodista que no descuide su tarea de confirmar la información recibida por este medio. 
Como señala Rheingold (citado en Espiritusanto, 2011, p. 9), el trabajo fundamental del periodista será la verificación de la información y "las pistas que reciben de los ciudadanos"; además de que "no hay garantía de que la información que llega de primera mano sobre una noticia sea cierta. La verificación de la información recibida se ha convertido en una labor incluso más importante que la fuente de la noticia".

Entre los medios de comunicación que más alientan el uso del WhatsApp en sus audiencias, interesa destacar el caso de los canales temáticos de noticias. Ellos realizan una amplia promoción al número de WhatsApp de sus redacciones, anuncio que es realizado tanto durante la emisión de los informativos como en sus redes sociales.

Para estas promociones utilizan el logotipo de WhatsApp seguido del número de contacto, acompañado además de un mensaje oral en el que piden a sus televidentes que "envíen sus denuncias". Mientras que en sus redes sociales de Twitter y Facebook el mensaje es similar, tal como el caso de RPP Noticias que señala: "Si tienes alguna denuncia llama al 438-8008 o mándanos tu video a nuestro WhatsApp (951431013)".

Se evidencia así el reconocimiento que han hecho estos medios del enorme potencial de esta red de mensajería instantánea multimedia (texto, imagen, audio) y el contacto directo que ofrece con la fuente.

Ortells (2009, pp. 341-353) apunta que precisamente la imagen va a ser fundamental para poder contar cualquier tipo de información en televisión: "Sin imagen es casi imposible que un hecho pueda llegar a convertirse en noticia en el medio audiovisual por excelencia". Aunque también señala que, si se trata de un hecho en el que no se cuente con imagen, se podrá hacer uso de archivos de noticias relacionadas o de temática parecida, pero que en las próximas ediciones se deberá contar con la imagen de manera indispensable.

\section{Metodología}

Para realizar el análisis propuesto se aplicó una entrevista semiestructurada a los responsables de gestionar las informaciones que llegaban al WhatsApp de Canal $N$ y de RPP Televisión, debido a que son ellos quienes han establecido metodologías para aplicar filtros a la información que llega al medio a través de esta red social.

En el caso de Canal N, según el organigrama del medio, el Jefe de Mesa de Informaciones es quien cumple la función de seleccionar aquellos datos que serán trabajados por este medio. Este periodista tiene la misma 
jerarquía que los jefes de sección y, además de ser el responsable directo de la selección de los mensajes enviados por los espectadores, tiene bajo su cargo a los reporteros.

En el caso de RPP Noticias, la selección de datos proveniente de usuarios a través del WhatsApp es función del coordinador del Rotafono, que es el canal de comunicación entre la audiencia y el medio a través de un número de teléfono fijo y el WhatsApp. Este coordinador, que tiene la responsabilidad de seleccionar y verificar la información, trabaja bajo el paraguas del Editor de Actualidades y en coordinación con los reporteros del medio.

Es asi que la muestra la conforman un periodista con nivel de coordinación por medio. A ellos se les aplicó un instrumento semiestructurado que contó con 13 preguntas a fin de conocer cómo se administra la información que llega mediante ese canal, cómo es seleccionada y verificada.

La selección de estos medios se debe a que ambos son canales temáticos informativos y por ello tienen una mayor necesidad de contar con información constante, actualizada e inmediata. Estas características propias de sus formatos requieren de un mayor contenido informativo para completar su parrilla, la que consta de 14 horas y 30 minutos en promedio de programas informativos, a diferencia del promedio de siete horas de los canales tradicionales de programación variada.

Además, ambos son canales de señal cerrada o de cable, que requieren de una suscripción para poder acceder a ellos; tienen un contenido bastante similar, ya que ambos brindan información sobre política, regiones, economía, sociales, internacional, deportes y espectáculos.

No obstante, existen ligeras variaciones en torno a la génesis de su producción informativa. Por un lado, Canal $N$ fue el segundo medio creado en la televisión peruana dedicado exclusivamente a noticias. Lanzado solo un año después de Cable Canal de Noticias (1998), se trató de un medio concebido por el peruano Diario El Comercio, como un espacio de información independiente. Años más tarde, Canal N se fusiona con América Televisión, uno de los canales de televisión más antiguos del país, y crean juntos una unidad informativa.

RPP Noticias, por su parte, vio la luz en el 2011, varios años más tarde que Canal N. No obstante, al ser parte del Grupo RPP, dueño de la radio de noticias vigente más antigua del país y con mayor credibilidad, desde su inicio, tiene un marcado respaldo en su producción informativa. Además, algunos programas son emitidos a la vez tanto por televisión como por radio. 
Importa señalar que ambos canales de noticias comparten el número de WhatsApp con sus multiplataformas. Así, en el caso de Canal $N$ el número de contacto de WhatsApp es también presentado como Alerta Noticias del canal de señal abierta América Televisión. En tanto que en el caso de RPP Televisión, el número de WhatsApp es compartido con su plataforma en radio, que también se llama $R P P$.

Para esta investigación también se realizó un análisis de las noticias de ambos medios y su clasificación de acuerdo con el criterio de interés general en el periodismo de televisión señalado por Estremadoyro (2014), del que a su vez se hizo una división según a) proximidad, donde de acuerdo con su repercusión serán divididas entre distritales, locales, nacionales e internacionales; y b) enfoque de la noticia, donde se hace la división según: interés humano, denuncia y suceso.

En interés humano se ubican los datos que son de interés general por su carácter humanitario; mientras que en denuncia se engloban aquellos que son de interés general porque buscan justicia o enmienda de algo que está mal, a través de la denuncia pública. En tanto, se agrupa en suceso aquellos datos que son de interés general porque revelan una situación problemática que el usuario presenció, pero que no necesariamente le afecta de manera directa.

Asimismo, se incluye una clasificación de acuerdo con el recurso audiovisual empleado en la elaboración de la noticia. En esta clasificación encontramos tres tipos de informes: a) elaborados con material audiovisual recibido a través del WhatsApp; b) elaborados con material propio del medio; c) elaborados con material mixto, pues se utiliza material propio con material proporcionado por el ciudadano.

Las noticias seleccionadas, por su parte, corresponden al período que abarca del 1 de julio del 2018 al 31 de octubre del 2018 y solo se seleccionaron aquellas que fueron presentadas verbal o textualmente en los noticieros como generadas a partir de información que llegó por dicha red social al medio.

\section{Resultados de la investigación}

Con base en la metodología descrita, se aplicó las entrevistas a Susana Gaona, miembro del equipo de Mesa de informaciones de Canal N; y a Junior Santa Cruz, coordinador del área de Actualidad de RPP Noticias. Ambos tienen a su cargo, según su turno, la labor de gestionar los mensajes que llegan al WhatsApp de sus medios. 


\section{Sobre la información que reciben}

Ambos coinciden en que reciben una gran cantidad de información, en su mayoría catalogada como información con enfoque de denuncia. No obstante, también reconocen que les llega mucha noticia falsa o trucada. Además, ambos señalaron que muy pocos emisores revelan su identidad o se presentan al momento de enviar un mensaje (20\%).

Asimismo, Gaona afirmó que este canal es usado también por los ciudadanos como un canal de comunicación para alertar sobre algunos errores en la emisión de una nota como puede ser el caso de la redacción en un banner o cintillo.

\section{Sobre el número de mensajes que reciben al día}

El número de mensajes que recibe Canal $N$ al día es en promedio 2.000, en tanto que en RPP Noticias es solo de 200. La gran diferencia se debe a que mientras Canal $N$ publicita este número de celular como contacto en los dos canales de televisión de su grupo informativo: Canal N y América Televisión, RPP promociona hasta cinco distintos números telefónicos en su plataforma de radio, siendo la mayoría de ellos teléfonos fijos que ya formaban parte del Rotafono, otro canal de contacto de la Mesa de Informaciones con el ciudadano.

\section{Mecanismos de selección de información}

Ambos coinciden en señalar que la magnitud del suceso o de la denuncia prima en la selección de la información. Esta debe tener relevancia y ser de interés general. Sin embargo, aseveran que la gran mayoría de información que llega de los ciudadanos por esta vía refleja que no conocen sobre los criterios periodísticos y que envían información sobre temas cercanos a ellos, como una queja de una demora de atención en el hospital de un familiar. "La gente confunde una denuncia con una queja”, expresó Santa Cruz en la entrevista.

Además, se toma en consideración que algunas noticias donde se señala que corre riesgo la vida de una persona o un grupo de personas, pueden salir al aire de manera inmediata, mientras que otros tipos de denuncias pueden esperar a que sean cubiertas por un reportero.

Por su parte, Gaona consideró también relevante que la información venda visualmente, por lo que siempre pide mayor cantidad de imágenes al ciudadano, a fin de evaluar si la nota podrá realizarse. 
En tanto, Santa Cruz también se refirió al recurso visual para la selección de la información, aunque consideró que muchas de las imágenes que brindan los ciudadanos pueden ser muy crudas, y no pueden emitirse en un canal de noticias.

Ambos periodistas concuerdan en que, del total de la información que es brindada por WhatsApp, solo el 5\% sirve para ser utilizada en el noticiero. Este porcentaje es el resultado de la selección de la información y de la posibilidad de verificación que se tenga de la misma.

De otro lado, el 95 \% de la información brindada a través de mensajes de texto que no es seleccionada es agradecida por el medio con mensajes como "Gracias por la información".

\section{Sobre verificación de información}

Si bien Santa Cruz reconoció que los medios de comunicación al inicio pudieron cometer errores y descuidos en la verificación del material recibido desde la implementación del uso del WhatsApp, considera que en el caso de RPP se supo aprovechar la experiencia de corroboración de información del Rotafono, un servicio de denuncias de su prestigiosa plataforma radial.

Así, de acuerdo con la entrevista, ambos medios señalaron que se sirven de otras fuentes adicionales para verificar la información. Entre ellas destacan a los agentes de seguridad municipales (conocidos en Perú como Serenazgo), la policía, los bomberos y otras instituciones de servicios.

Otra forma de verificación que consideró importante Gaona, y que a la vez aseveró que genera más contenido, es solicitar a la misma fuente del WhatsApp mayor número de imágenes del suceso, para lo que ella les da ciertas indicaciones.

Santa Cruz consideró también como una forma de verificación la coincidencia en el tiempo de un número elevado de mensajes.

"Si en el momento te llegan imágenes de un suceso denunciado por más de cinco personas a la vez, y que el hecho continúa en aumento, es señal de que algo realmente está ocurriendo, y en tanto se verifica con alguna fuente adicional, se va enviando a una unidad a cubrir el hecho", apuntó.

Asimismo, señaló que también realizan la revisión de otras redes sociales de otros usuarios que no hayan necesariamente tenido contacto con el medio para presumir que se trata de un hecho real. 
Santa Cruz explicó que tras ese ejercicio de verificación ya se pasa a evaluar si la información tiene la relevancia para ser presentada como una alerta informativa.

Las nociones de la realidad también son muy importantes. Santa Cruz consideró que para el periodista es fundamental prestar atención a ciertos detalles que reflejen la veracidad de la imagen: el estado actual de las calles, el clima actual, entre otros. "Si todo el día estuvo soleado, y te mandan una imagen de Lima gris como si se tratase de hoy, es que algo no corresponde", apuntó.

Asimismo, señaló que es importante que el periodista a cargo tenga ciertas nociones sobre manipulación de la imagen.

Gaona consideró también que muchos ciudadanos colaboran con la verificación de la información. Sobre todo en los lugares de menor acceso. De esta manera, los periodistas piden que les brinden el nombre de la comisaría más cercana de sus localidades a fin de que ellos puedan tomar contacto con la policía y confirmar el hecho mediante esta fuente.

\section{Análisis de noticias emitidas con base en información de WhatsApp}

Las noticias analizadas para el desarrollo de esta investigación pertenecen a la producción periodística de los canales de televisión RPP Noticias y Canal N durante el período de tiempo del 1 de julio al 31 de octubre del 2018, período en el que también se llevó a cabo las entrevistas para esta investigación.

Con relación a la cantidad de noticias analizadas pertenecientes a Canal $\mathrm{N}$, estas fueron un total de 20, mientras que en RPP fueron un total de 25.

Cabe precisar que solo se seleccionaron las noticias que fueron presentadas verbalmente o textualmente como generadas a partir de información que llegó al WhatsApp del medio.

En cuanto a la variable de proximidad, RPP Noticias registra que en su mayoría estas corresponden al tipo de noticias locales (56\%); es decir, aquellas que refieren acontecimientos que tienen lugar y repercusión directa para los habitantes de la ciudad de Lima. Por otro lado y con menor intensidad, las noticias distritales (36\%) ocupan un menor porcentaje en la selección informativa.

Lo opuesto ocurre en el caso de Canal N, donde las noticias distritales (55\%) tienen mayor presencia que las locales (35\%) en el desarrollo de sus notas 
periodísticas. Cabe resaltar que las noticias distritales únicamente abordan temas correspondientes a espacios limitados, y que, por lo tanto, afectan a sectores específicos de la población.

Finalmente, las noticias nacionales representan el menor porcentaje de aparición en la muestra, tanto en el caso de RPP (8\%) como en el de Canal N (10\%).

Tabla 1. Noticias analizadas según su proximidad

\begin{tabular}{|l|c|c|c|c|c|c|}
\cline { 2 - 7 } \multicolumn{1}{c|}{} & \multicolumn{2}{c|}{ Canal N } & \multicolumn{2}{c|}{ RPP TV } & \multicolumn{2}{c|}{ Total } \\
\cline { 2 - 7 } \multicolumn{1}{c|}{} & Cantidad & Porcentaje & Cantidad & Porcentaje & Cantidad & Porcentaje \\
\hline Distrital & 11 & $55 \%$ & 9 & $36 \%$ & 20 & $44 \%$ \\
\hline Local & 7 & $35 \%$ & 14 & $56 \%$ & 21 & $47 \%$ \\
\hline Nacional & 2 & $10 \%$ & 2 & $8 \%$ & 4 & $9 \%$ \\
\hline Internacional & 0 & $0 \%$ & 0 & $0 \%$ & 0 & $0 \%$ \\
\hline
\end{tabular}

Fuente: Elaboración propia

De otro lado, según su enfoque, las informaciones de denuncia son las que más se presentan vía WhatsApp (60\%), seguidas de las de suceso (31\%). En el caso de RPP Noticias el enfoque de denuncia representa el $72 \%$ de la totalidad de noticias elaboradas; mientras que en Canal N significan el $45 \%$ de los mismos. En RPP Noticias también se utiliza la información de interés humano (16\%).

Tabla 2. Noticias analizadas según su enfoque

\begin{tabular}{|l|c|c|c|c|c|c|}
\cline { 2 - 7 } \multicolumn{1}{c|}{} & \multicolumn{2}{c|}{ Canal N } & \multicolumn{2}{c|}{ RPP TV } & \multicolumn{2}{c|}{ Total } \\
\cline { 2 - 7 } \multicolumn{1}{c|}{} & Cantidad & Porcentaje & Cantidad & Porcentaje & Cantidad & Porcentaje \\
\hline Suceso & 11 & $55 \%$ & 3 & $12 \%$ & 14 & $31 \%$ \\
\hline Denuncia & 9 & $45 \%$ & 18 & $72 \%$ & 27 & $60 \%$ \\
\hline Interés Humano & 0 & $0 \%$ & 4 & $16 \%$ & 4 & $9 \%$ \\
\hline
\end{tabular}

Fuente: Elaboración propia

Se observa también que el registro audiovisual de la información y el ejercicio reporteril son predominantes aun para los canales de noticias. Por ello, 
según el análisis, aun cuando la información es brindada primigeniamente por el WhatsApp, muchas veces se acude a la presencia de un reportero en el lugar. Así, se observa que en el caso de RPP Noticias, este ejercicio se realiza en un $80 \%$ de las notas; en tanto que en Canal $N$ en un $35 \%$. Por el contrario, se observa que en Canal $N$ predomina el uso del material enviado por los ciudadanos (65\%).

También se presentan las notas con contenido audiovisual mixto: donde tanto el material propio como el enviado por algún ciudadano son utilizados para el desarrollo de la nota. Así lo demuestra RPP Noticias, aunque esto ocurre en menor porcentaje (16\%).

Tabla 3. Noticias analizadas según el recurso audiovisual utilizado

\begin{tabular}{|l|c|c|c|c|c|c|}
\cline { 2 - 7 } \multicolumn{1}{c|}{} & \multicolumn{2}{c|}{ Canal N } & \multicolumn{2}{c|}{ RPP TV } & \multicolumn{2}{c|}{ Total } \\
\cline { 2 - 7 } \multicolumn{1}{c|}{} & Cantidad & Porcentaje & Cantidad & Porcentaje & Cantidad & Porcentaje \\
\hline $\begin{array}{l}\text { Material enviado } \\
\text { al Whatsapp }\end{array}$ & 13 & $65 \%$ & 1 & $4 \%$ & 14 & $31 \%$ \\
\hline $\begin{array}{l}\text { Material del canal } \\
\text { (Reportero) }\end{array}$ & 7 & $35 \%$ & 20 & $80 \%$ & 27 & $60 \%$ \\
\hline Mixto & 0 & $0 \%$ & 4 & $16 \%$ & 4 & $9 \%$ \\
\hline
\end{tabular}

Fuente: Elaboración propia

\section{Conclusiones}

Los resultados de la investigación permiten conocer una parte importante del uso del WhatsApp por los periodistas de los canales de noticias y sus audiencias. En relación a lo que plantea Gillmor (citado en Maciá, 2007, p. 127), los periodistas reconocen que las audiencias están más cerca de los hechos y por ello les brindan un espacio de contacto directo con la unidad de mesa de informaciones como es el número de teléfono conectado a WhatsApp. Como dice Varela (2005, p. 20), "únase a los ciudadanos o la audiencia lo arrollará".

No obstante, según las entrevistas realizadas, ambos periodistas responsables de gestionar la información que llega al WhatsApp coinciden en que el ciudadano no tiene la formación ni el criterio periodístico para reconocer una noticia, y que algunas veces las noticias que envían son 
falsas. Esto condice con lo que anotaba Sánchez en Espiritusanto y Sánchez (2013) en relación con la inexistente formación periodística del ciudadano, así como la verificación de la información y la ética que sí tiene el periodista, a diferencia de quien no lo es.

De esta forma, vemos que la información recogida desde el WhatsApp termina siendo una fuente más del trabajo periodístico, que a su vez pasará por los criterios periodísticos tradicionales en los que tanto Estremadoyro (2014) como Coya (2017) incluyen los siguientes: interés general, actualidad, proximidad, personaje o personalidad, orgullo nacional, rating, entre otros; así como que exista una imagen (Ortells, 2009) para que esta información finalmente se convierta o no en noticia.

Contar con un contacto de WhatsApp amplía el número de posibles fuentes para los medios, como también aumenta la posibilidad de contar con una imagen del hecho, pues los ciudadanos tienen acceso a lugares y situaciones adonde quizá el medio de otra manera no hubiera podido acceder en el tiempo que la inmediatez del periodismo demanda. Es importante señalar también que esta potencialidad presenta al mismo tiempo ciertos reveses como (1). El exceso de datos, (2). La tentación de presentar una imagen potente que impactará al espectador y (3). La necesidad de confirmar rápidamente la información para tener la primicia informativa.

Se observa también, según el análisis de las noticias emitidas, que los defectos de los criterios periodísticos tradicionales en televisión se trasladan al tipo de selección que se realiza teniendo como fuente al WhatsApp. Así, tópicos como el centralismo de la agenda de los noticiarios permanece aún en este tipo de selección. Como señala León (2006, p. 277), existe una "notoria falta de compromiso con la diversidad territorial del ámbito siquiera nacional" en el periodismo de televisión, que muchas veces se ha justificado con la focalización de los recursos técnicos en la sede central de los medios.

Queda demostrado que incluso en las noticias que parten de una fuente de WhatsApp se repite el centralismo de los medios, tal como se ve en RPP Noticias, donde un 92\% de su información es distrital de Lima o local, en referencia a Lima Metropolitana (que incluye a la región Callao). Situación similar ocurre en Canal $\mathrm{N}$, con un $90 \%$ de noticias que son distritales o locales.

Todo ello aun cuando la información seleccionada por los medios puede generarse en otras zonas del país, y a pesar de que, según los resultados sobre el enfoque, dicha información es en mayor medida de denuncia (RPP con 72\% y Canal $N$ con un $45 \%$ ), seguida de sucesos (RPP con $12 \%$ y Canal $N$ con $55 \%$ ). 


\section{Referencias}

Azeema, N. \& Nazuk A. (2017). WhatsApp and Journalism: News Practices of Pakistani Journalists. Science, Technology and Development, 36(4), 249-258. Recuperado de https:// www.researchgate.net/publication/323187133_WhatsApp_and_Journalism_News_ Practices_of_Pakistani_Journalists

Bowman, Sh. \& Willis, Ch. (2003). Nosotros, el medio: Cómo las audiencias están modelando el futuro de las noticias y de la información. Recuperado de http:/ / www.hypergene.net/ wemedia/download/we_media.pdf

Carabaza, J. \& Pérez, G. (2014). Dime a quién sigues y te diré quién eres. Análisis de las cuentas seguidas por los diarios Vanguardia, Diario de Coahuila y Zócalo a través de Twitter. Revista Latinoamericana de Ciencias de la Comunicación, 20(11), 140-147. Recuperado de https://www.alaic.org/revista/index.php/alaic/article/view/376

Chillón, J. (2010). Oportunidades y amenazas del periodismo ciudadano en la sociedad globalizada. Eikasia Revista de Filosofía, 31, 295-308. Recuperado de http://www. revistadefilosofia.org/31-16.pdf

Coya, H., (2014). El Periodista y la Televisión. Lima, Perú: Fondo Editorial de Pontificia Universidad Católica del Perú.

Curiel, E., (2015). La credibilidad de las redes sociales en el ámbito periodístico., Transinformação, 27 (2),165-171. Recuperado de https:/ / www.redalyc.org/ html/3843/384351520006/

Espiritusanto, O. (2011). Los usuarios. Tipología de la participación. En Espiritusanto, O. \& Gonzalo,P. (Ed.), Periodismo ciudadano. Evolución positiva de la comunicación (pp. 15-18). Barcelona, España: Editorial Ariel. Recuperado de https://www.revistacomunicar. com/pdf/2011-12-15-libro-periodismo-ciudadano.pdf

Espiritusanto, O. \& Sánchez, G. (2013). Periodismo ciudadano: argumentos a favor y en contra. Cuadernos de Periodistas, 27, 56-71. Recuperado de http://www. cuadernosdeperiodistas.com/media/2014/02/56-71-INFORME_periodismo-ciudadano.pdf

Estremadoyro, J., (2014). Lecciones de periodismo televisivo, Lima, Perú: Fondo Editorial Pontificia Universidad Católica del Perú.

GfK Opinión (2017). Kit de planeamiento digital Perú 2017. Recuperado de https://cdn2. hubspot.net/hubfs/2405078/Landing_Pages_PDF/Peru/GfK\%20uso\%20de\%20 internet\%202016\%20-\%20Short.pdf?t=1527257187799

Kemp, S. (2018). "Digital In: Informe sobre El ámbito digital en el 2018 y su situación mundial desde Argentina hasta Zambia". We are social. Recuperado de https:// hootsuite.com/ es/pages/digital-in-2018

León, T. (2006). La agenda de los noticiarios. En J. Fernández (Coord.), Tendencias 06 - Medios de comunicación (pp. 271-279). Madrid, España: Fundación Telefónica. Recuperado de https://dialnet.unirioja.es/servlet/articulo? codigo=4990825

Maciá, C. (2007). No todos somos ya periodistas. Un análisis de la utopía del periodismo ciudadano desde la perspectiva del reportaje interpretativo. Estudios sobre el Mensaje Periodístico, 13, 123-144. Recuperado de http://revistas.ucm.es/index.php/ESMP/article/ view/ESMP0707110123A 
Meso, K. (2005). Periodismo ciudadano. Voces paralelas a la profesión periodística. Chasqui Revista Latinoamericana de Comunicación, 90, 4-13. Recuperado de https:// dialnet. unirioja.es/servlet/articulo? codigo $=1203580$

Meso, K. (2013). Periodismo y audiencias: inquietudes sobre los contenidos generados por los usuarios. Revista Cuadernos, 33, 63-73. Recuperado de http://cuadernos.info/index. $\mathrm{php} / \mathrm{CDI} /$ article/view/cdi.33.515

Ortells, S. (2009). La mercantilización de la información: la nueva era informativa en televisión. Revista Latina de Comunicación, 64, 341-353. Recuperado de https://doi. org/10.4185/RLCS-64-2009-827-341-353

Ossorio, M. (2016). WhatsApp para periodistas: cuando las fuentes están en la palma de tu mano. Madrid, España: Media-Tics. Recuperado de https://www.media-tics.com/ noticia/6425/medios-de-comunicacion/whatsapp-para-periodistas:-cuando-lasfuentes-estan-en-la-palma-de-tu-mano.html

Reid, A., (2016). WhatsApp at 1 billion: How can journalists use the chat app for newsgathering? First Draft. Recuperado de http://firstdraftnews.com/whatsapp-at-1billionhow-can-journalists-use-the-chat-app-fornewsgathering/

Salvat, G. \& Serrano, V. (2011). Periodismo ciudadano y espacio público en la Sociedad de la Información. Anàlisi: Quaderns de comunicació i cultura, 41, 69-85. Recuperado de https:// www.raco.cat/index.php/analisi/article/viewFile/244644/327666

Varela, J. (2005). El asalto de los medios sociales. Cuadernos de periodistas, 0, 18-32. Recuperado de https://dialnet.unirioja.es/servlet/articulo?codigo=5336040

Welsh, M. (2015). The New York Times is publishing on WhatsApp for the first time, covering Pope Francis. The New York Times. Recuperado de http:/ / www.niemanlab.org/2015/07/ the-new-york-times-is-publishing-on-whatsapp-for-the-first-time-covering-pope-francis/ Zárate, C. (2018). Cómo sirve WhatsApp a los periodistas. Perú: Clases de periodismo. Recuperado de http://www.clasesdeperiodismo.com/2018/04/10/como-sirve-whatsappa-los-periodistas/ 